\title{
DESIGN PROCESS AS COMPLEX SYSTEM
}

\author{
R. BARELKOWSKI \\ West-Pomeranian University of Technology, Szczecin, Poland.
}

\begin{abstract}
Can a design process be complex system? Can it fulfill various criteria related to complexity, while its goals are, usually, temporarily defined and the process itself is expected to provide particular solutions transferable into physical volumes and solid environmental components?

It is apparent that the majority design cases do not follow traits and requirements of complexity, but this limitation seems to be related to natural tendency of simplification within architectural routines. Particularly public works, significant for the community, require the approach broadening the scope of understanding of spatial phenomenon, its role and its composition as a result of various programmatic, ideological, formal, and engineering aspects, embedded in complexity theoretical background.

Seven principal components of complexity, given by Rzevski and Skobelev, are more or less explicitly or implicitly present in design practice, and in particular, in design process: connectivity, autonomy, emergence, non-equilibrium, nonlinearity and self-organization. The aspect of evolution is the least apparent and there are significant limitations to what can be achieved there, mostly the process can evolve, while designed substance rarely can follow in the same flexible manner. In the paper I will argue that approach related to complexity is the general mode of architectural design, simplified in many cases due to human inclination to reduce the number of simultaneously processed problems and usually resulting in some design flaws or failures. This complex structure of design process, exemplified in the paper as a particular research case - the process for local cultural center - is the basis, which can be furthermore simplified, contrary to the idea that it is more sophisticated, non-standard approach. Working not only with the client, but with various types of users is a typical architectural condition, implementing significant constraints and at the same time forcing multiple organization arrangements within the process. The case will provide the platform to discuss broader idea of design as complex environment for the architect.

Keywords: architectural design process, complex system, complexity, Meta-Design
\end{abstract}

\section{INTRODUCTION}

The architectural design process is a multifaceted phenomenon reflecting plentitude of diverse disciplines and aspects of human life projected onto human organization of their environment. Interpretations of this phenomenon are countless and discussing of this issue inevitably encourage the narrowing of the scope of any research conducted in order to understand its principles, even if. It is necessary to define the aim of this particular paper being a prolegomena for understanding the design process as a decision-making process immersed in the framework disclosing the complex nature of design. Therefore I will advocate to understand the architectural design process as complex system, which most often is reduced to its simplified form due to practical constraints of massive and multiple use, frequent application devoid of an effort of understanding reasons and motivations other than those required to straightforwardly fulfill the task at hand. I argue that regardless of how profound the impact of complexity theory has on architecture in context of critical analyses elements of architectural epistemology have inherent components of complex system seen in every design process.

The scientific approach to architectural design dates back to general engineering design research, and therefore it was built on foundations laid by Asimov et al. [1], Krick et al. [2], to name the few. Starting from simple, linear concepts of the advancement of the process like Asimov's model [3] or interdisciplinary depictions like in case of Krick [4], researchers 
attempted to delineate the course of design which, however, was incompatible with the discipline of architecture mainly because of the fundamental difference described by John Zeisel. Zeisel noticed that architectural goals, reflecting disciplinary problems, are established in completely different manner, than typical engineering goals, and to put it briefly that instead of seeking optimization architects seek for imprecise state of acceptance [5]. The observation came as a conclusion and criticism of attempts to use algorithms as basic, fixed building bricks of architectural practice, both to determine the solutions, and to determine the organization of design process. It was also connected strongly to the realization how important social issues, not to mention cultural issues, are in every architectural work.

\section{ARCHITECTURAL COMPLEXITY - A BRIEF PANORAMA}

Historically intuitive design dominated and still is the most often form of architectural practice. However intuitive mechanisms are insufficient when it comes to managerial abilities combining, for example, technical, technological, aesthetical, social and economical aspects. Every design process in architecture is a reflection of social life and at the same time an attempt to process various types of data as well as transform physical components in order to improve human-centered environment, and relying on gradual perfectioning of design skills, on context-driven ad hoc adjustments of already established routines is usually far from efficient. While architectural constructs - particular themes - may be less or more complex, and therefore both guidelines and recipe to tackle the problem should refer to general methodologies, encompassing all possible or at least majority of cases. Thus, research efforts are focused on finding universal understanding of architectural design process and it requires often overlooked concept of holistic approach to design, which so aptly Christopher Alexander refers to, when depicting his original contribution to design theory from the 1960s [6]. The most significant goal of architecture is to respond to or to extend rich and multilayered reality, in which physical volume of architecture is merely a vessel for both human ideas and human pursuits connected with functional aspect. Since 1980s design process models evolved and spread depicting different valid intuitive or even purely technical (organizational) concepts like Robert Gutman's [7] or recently Lorraine Farrelly's [8], but at their best they are fragmentary and therefore significantly limited in their application.

Architectural science postulated more thorough and more systemic approach to the issue of the process. The introduction of systemic approach reaches as early as 1957 when Allen Newell, John Shaw and Herbert Simon presented their work on information processing theory, which was later respectively applied to architecture [9]. Within the field of architecture, however, system appeared too rigid, and some of principles, like eight implications of the concept of a system collected by Arnold Benjamin Handler, didn't correspond to specific architectural problems [10], but at the same time some of these suggest the potential, later developed as part of so-called environmental model of design advocated by Jon Lang [11] and later on complexity approach. As Antoine Picon writes in his essay on continuity, complexity and emergence, the term complexity may be used in multiple ways, and his own thoughts concentrate on the digital design as an evolved form of contemporary, most recent background for ideas in architecture [12]. On the one hand, the philosophical discourse in architecture approved digital technologies as a source of new and adequate language, and therefore allowing to merge abilities offered by the new media with flourishing creativity opposing traditional ideals of pursuing perfection in architecture - instead responding to virtualization and to blurring of borders between the real and the simulation. On the other hand, Picon confirms that complexity can go further, implicitly referring to increased 
diversity and multi-threadedness of the environment with its split, yet mutually supplementing counterparts of the real and the virtual, posing more challenges for architects [13]. Little, however, we may find there regarding the role of the architecture - and this is where Alexander's understanding of architectural complexity proves its validity [14]. What is really important about Alexander's idea of complexity implementation is in the approach to holistic view of architecture, in integration between objective, objectivized, and subjective components of the design process. Contrary to self-contained problems and resultant processes, architects are expected to respond to real world even if important parts of this reality is virtual. Complex system is too valuable to employ it for fancy, theoretical deliberations, instead of offering visual manifestation instead of, what Michael Mehaffy and Nikos Salingaros define as connective and coherent complexity [15]. Both researchers see complexity as a platform to successfully reflect and address essential problems of architecture - for people.

\section{COMPLEXITY MODEL IN ARCHITECTURE}

Diverse concepts of architecture, or particularly architectural design process, link it to complexity theory primarily through two secondary level ideas - first, the understanding of architecture as immaterial environment constructed by people for themselves, containing all, even unintended elements, and second, the process and all its constituents and stimuli. One can see here a clear pattern: the reality and its preceding moderation. Within complexity architecture exists as rich, complex phenomenon, in which physical volumes are merely vessels for socio-cultural contents. It respects architecture as what defines physical components to organize, but these volumes and delimitations are nothing but results, symptoms of social and cultural processes. The architectural design process is aimed at transforming observed reality giving it an altered state, an improvement. Therefore elements of analysis, observation, comprehension come along with carefully constructed prediction. The process, even implicitly, aspires to provide positive change - more as a program suggesting appropriate steps to be undertaken in order to receive planned status.

The presence of prediction assumes uncertainty - in result implying necessity to contain unplanned, emergent phenomena or issues which may and will surface during either planning, designing or executing, occupying. What's more, design cannot be hierarchical - and it's not the issue of in-processual loops, but overall structure - and it also cannot be ahierarchical. It is clear that architect is responsible for building the system of criteria for every project, but this system must be flexible and sometimes must be rebuilt from scratch, even several times, within particular task. We may conclude, therefore, that architectural projects, or more precisely design processes, tend to become compatible with complexity desiderata.

Seven principal components of complexity were gathered by George Rzevski and Petr Skobelev: connectivity, autonomy, emergence, non-equilibrium, nonlinearity, self-organization and co-evolution [16]. It is hard to discuss the transformation of reality that constitutes architectural environment and how architectural profession is performed, but it is worth mentioning that many of complexity criteria respond to increased consciousness of customers, users of space, developers and clients from public sector - the architectural task, which was once focused on providing shelter or exposing social role, nowadays fulfills all these roles extended with many more concepts like the issue of comfort (reflection of lifestyle), safety, architectural semantics, programming spaces for the use of groups or congregations [c.f. Table 1]. The example of such was delivered by Rena Upitis in her study of school designs [17], and complexity evidently plays significant role in large scale architectural designs, 
Table 1: Criteria of complexity and their application in the field of architecture.

\begin{tabular}{l} 
Complexity criteria \\
\hline Connectivity \\
responds to emergence \\
connects directly to au- \\
tonomy \\
contributes to nonlinearity, \\
self-organization and co- \\
evolution \\
Autonomy \\
responds to emergence \\
connects directly to con- \\
nectivity \\
contributes to nonlinearity \\
and self-organization
\end{tabular}

\section{Emergence}

(rarely) responds to selforganization connects directly to nonequilibrium contributes to connectivity, autonomy, nonlinearity and co-evolution

\section{Non-equilibrium}

responds to emergence and co-evolution connects directly to selforganization contributes to connectivity and nonlinearity

\section{Nonlinearity}

responds to emergence, non-equilibrium and self-organization connects directly to connectivity and autonomy

Architecture

Various components of actual spatial program - and in result spaces themselves, whether in urban or architectural scale, collectively and dynamically negotiate its role

Various components of actual spatial program - and in result spaces themselves operate independently

Socio-cultural events or interactions emerge in configured space (environment), unpredictable use appears

Any arrangement between architectural components is unstable; even if it tends to balance, this state can never be effectively acquired

Continuity is represented in space by spatial-temporal sequence, but this continuity is defined by random events and drivers, potentially re-orienting the use of architectural/urban space
Architectural design process

\section{Intradisciplinary and inter-} disciplinary networking general issues influence detailed considerations, detailed decisions affect principles, integration, interdisciplinary or transdisciplinary perspective is applied to the process

\section{Ability to accommodate exclusive}

specific branches and themes are independent and may conditionally operate regardless of other branches / themes as long as other criteria do not trigger reconfiguration

\section{Inclusion (responsive) mechanisms}

acknowledgment of unpredictable decision-shifting (sudden) factors / agents; recalibration of the remaining process (or extension of the process), generation of selfinduced alterations to process

Permanent fluctuation (flexible structure)

the process tends to reflect architect's personal evaluation system; however, it fluctuates constantly in response to new criteria or new relationship between criteria

\section{Open architecture of the} process

design process is performed in parallel network threads or cells and there are no sequential steps (but for contractual purposes) 
Table 1: (Continued)

\begin{tabular}{|c|c|c|}
\hline Complexity criteria & Architecture & Architectural design process \\
\hline Self-organization & $\begin{array}{l}\text { Architectural/urban space } \\
\text { organizes its performance }\end{array}$ & $\begin{array}{l}\text { Permanent reconfiguration } \\
\text { (flexible structure) }\end{array}$ \\
\hline $\begin{array}{l}\text { responds to emergence and } \\
\text { non-equilibrium } \\
\text { connects directly to con- } \\
\text { nectivity and autonomy } \\
\text { contributes to nonlinearity } \\
\text { and co-evolution }\end{array}$ & $\begin{array}{l}\text { independently from its } \\
\text { creator or even commu- } \\
\text { nity that uses it; recon- } \\
\text { figuration, repurposing is } \\
\text { perpetual }\end{array}$ & $\begin{array}{l}\text { system of criteria for design } \\
\text { as well as any relationship be- } \\
\text { tween factors / agents may be } \\
\text { altered and constantly remain } \\
\text { open to further re-organization } \\
\text { depending on validity or } \\
\text { applicability of current one; } \\
\text { the structure is permanently } \\
\text { adjusting itself }\end{array}$ \\
\hline $\begin{array}{l}\text { Co-evolution } \\
\text { responds to emergence } \\
\text { contributes to connectivity, } \\
\text { autonomy, nonlinearity and } \\
\text { co-evolution }\end{array}$ & $\begin{array}{l}\text { Various elements of space } \\
\text { evolve in different rate and } \\
\text { diverse directions, yet } \\
\text { coordinate its interconnected- } \\
\text { ness }\end{array}$ & $\begin{array}{l}\text { Permanent evolution of } \\
\text { contents of the process } \\
\text { (flexible structure) } \\
\text { responsive modules within the } \\
\text { process }\end{array}$ \\
\hline
\end{tabular}

extending the notion of complexity used by Esra Bektaş, particularly in case of large public projects [18] in which uncertainty and resultant risk of failure are increased.

Rzevski and Skobelev bring forth additional issue - significant question of adaptability being a primary requirement of the system. This is clearly the case in almost all architectural tasks, and therefore, it qualifies to define the generic framework of design process. Making design process an adaptive system is requested because of multitude of factors - customers' alteration of expectations or criteria, responses to availability of particular solutions, dealing with substitutive material, technological or spatial solutions, changing budget constraints, among others. Rzevski and Skobelev mention real-time decision making, delayed commitment, minimizing consequences of disruptions, distributed decision-making, anticipation, experimentation and learning from experience [19].

Few of these adaptability traits urge for comment. Anticipation, or in more elaborated cases analysis-based prediction is not so obviously embedded into architectural design process. However clearly this element should be acknowledged in every design task - let us consider one of the simplest examples possible, which is detached family house. The anticipation is related not only to what customer wants today and tomorrow (e.g. children getting mature and leaving), but also what may happen to customer or their relatives (e.g. accidents, unpredictable disabilities). Naturally, in many components of design process this anticipatory aspect reflects varied level of requested ability to determine future performance of architecture, and the architect should be constantly aware to react and adjust the course of design respectfully. Learning from experience may be extended here by the inclusion of learning organization levels. As suggested by Robert Barelkowski, third level organization of learning [20], which is learning from learning supplements learning from designing, which is implied 'learning from experience'. Additional learning structure introduces axiological perspective, responsive methodological approach, adjustable value systems, and multi-disciplinary imports interwoven into rich 
tapestry of expanding professional knowledge management. Experimentation is the next topic which is altered by the application within the framework of complexity. It implies fragmented and dynamic experimenting with architectural concepts. Instead of organizing and subordinating the entire process to allow for design as experiment, the experimentation is divided into autonomous cells and launched contextually regarding the perspective of its necessity and efficiency. It is reflected in 'designing' the framework, being able to accommodate separate experimental activities performed simultaneously by different members of design team, in some circumstances even in purposefully uncoordinated manner. Distributed decision-making and real-time decision making are closely connected and appear in design process very overtly. Clear example of this feature may be given in the way installation or engineering designs may affect architectural part of solution. Certain constraints are driven by availability of technologies and services and may vary between what is available in time of particular decision is (initially) made and changes that are imposed by shortage of suggested conclusion. The progress of the project requires instant reaction and similar behavior is expected when conflict (e.g. aesthetical, between architecture and HVAC systems) appears. Delayed commitment is somewhat problematic in architectural implementation. On the one hand actually there is a suspension of final decision, but on the other hand design must deal with solid pieces of information, and therefore often working assumptions are taken into account. In the process this 'suspension' is counterproductive, and therefore, often replaced by multi-variant open solution, following temporarily particular concept with preparation for absorption of altered one or even rejection. In the latter case acceptance for rejection perspective is conditioned by several constraints or factors, like e.g. costs, technical ability to built-in the solution at particular stage of execution and probability of future use. This open multi-variant approach can often retain some elements of rejected, yet possible in the future further adaptations.

However, at the same time, an element of criticism must be invoked here to refer to the issue of information processing and knowledge processing. Architectural problems are significantly different from engineering problems, and in result contain much larger share of subjective or intersubjective stimuli. This in turn leads to higher instability, higher risk of failures - whether partial or total. Also, both groups of social and cultural factors are prone to the quality of interpretation - causing the risk of misguidance in creating relevant managerial mechanisms. Also, many researchers point out that human component or human factor, to be appropriately respected, should encourage direct participation of people, users of architecture, in the process contrary to usual use of, for example, IT tools supplementing the behaviors of various elements of the system [21, 22]. People add unparalleled unpredictability and creativity both as contributors and decision-making agents, despite certain amount of flaws or errors that may be generated as a result of merging the digital and the analog (or social).

\section{COMPLEXITY IN ARCHITECTURAL PROJECT}

Quite often theory provides interesting paths to explore, but practice not necessarily recognizes the opportunity to apply it. And architectural practice is the optimal way to prove or disprove the abovementioned theoretical assumptions. While this paper discusses rather the theoretical framework and does not intend to formulate the thesis and advocate for it, one of design applications may be used as partial reference to extend the discourse on complexity into several practical issues used to explore universal nature of application of complexity in architectural design process.

The project of Oborniki Cultural Center (OOK) provided a unique opportunity to perform architectural design, in which there were several elements justifying the implementation of complexity. First of all, the need for new cultural center, built on existing, yet very modest 
components, was leaving the ambiguity space as to what this new center should become, how it should be programmed, and to which ideas it should refer in order to develop bond between people (future users) and conceived architecture on the one hand, and on the other hand to have a flexible functional solution, rich, but not excessive aesthetic proposal. Simultaneously approaching physical structure and technical requirements multiple issues derivative from the former, confronted with economic and organization related constraints. This represents two levels of engaging complexity - conceptual and definite, latter simply adds various elements to the process (conceptual part remains open for corrections or changes).

The center is planned to serve the community of 35.000 people in 2020 and around 45.000 inhabitants in 2050. The project refers to the old cultural center with current seat in two buildings complex, larger one with main multi-purpose hall in standard relevant to 1980s, and smaller with upper level with insufficient height. Approximate net surface included in the program is $7000 \mathrm{~m}^{2}$. Project is aimed at delivering the ultimate yet flexible proposal for the development of the center, providing multi-purpose hall, auditorium with relatively large stage and backstage. New building and the arrangement of its surroundings should provide space for social integration, and contextually it should become the main public node for southern part of the town of Oborniki. This particular case is very appropriate because its initial definition is very vague - in fact neither local authorities, nor local community know what ultimately should be the result of the project. There is only an approximation of programmatic assumptions, but the program remains open to any suggestions. There is no ideological content which anyone would like to absorb in architectural form of the building. There are strongly limited resources and financial support, but nobody ever before conducted an analysis on connection between program and investment and maintenance costs.

The project requires the formation of socially binding idea, establishment of the program, functional definition in both terms - architectural and urban. This abstract or disciplinary range of problems is furthermore supplemented with more direct, engineering, technical, or organization-oriented questions, making a network of various factors or agents. While detailed analysis of the structure of design process for OOK goes beyond the scope of this paper, it is still worth noticing that mentioned network corresponds to multiple semi-independent nodes relevant to specific problems or disciplinary issues. For example, economic aspect is depicted by two major groups - expenses and revenues, on lower level expenses refer to physical elements (e.g. shell, loadbearing structure, materials and installations), to media (e.g. energy and water), to manpower or required employment, and revenues, apart from predictable savings, rental revenues, include calculation related to identity gains (brand), social capital gains, etc. One of multiple nodes assumes both internal and external dynamic relationships and shifting - with evolving budget assumptions for particular architectural configuration, which adjusted, imposes reconfiguration among those elements, that are activated in selected setting. This type of organization facilitates otherwise complicated decisions, and this reductive ability does not hamper precision, relevance, and grasp of holistic approach in detailed activity. This process of facilitation relies on exchanging stipulated holistic analysis of the course of the project with series of isolated or connected, extracted little contributions - their impact usually of a small scale, with opportunity to further alterations to seemingly fixed decision. Every content of the project structure was substituted by the factor (or the agent) and the relationships between factors (agents) have been defined as a simple catalogue filled and justified thematically and contextually, but simplified as output for the system. Every factor has stable component and dynamic component, and it may switch its status (from stable to dynamic and vice versa). These interactions could be investigated to find out how complexity can be managed in OOK case study, as shown in connection to Table 2 and Table 3. 
Table 2: Catalogue of possible interactions between factors / agents:

Factor / agent A operates at or gets the same level as factor / agent B (has similar $\quad$ A $\leftrightarrow$ B impact on decision-making)

Factor / agent A operates at or gets higher level as factor/agent B and thus A has $\quad \mathrm{A} \rightarrow \mathrm{B}$ precedence (has higher impact on decision-making)

Factor / agent A operates at or gets lower level as factor / agent B and thus B has $\quad \mathrm{A} \leftarrow \mathrm{B}$ precedence (has higher impact on decision-making)

Factor / agent A operates independently from factor / agent B and thus A and B have no interconnection (difference on impact on decision-making cannot be determined) Factors / agents A and B are simultaneously altered by external driver

One of factors / agents A or B is altered by external driver

$\mathrm{A} \approx \mathrm{B}$

Factor / agent A alters factor / agent B status

$\mathrm{A} \propto \mathrm{B}$

Factor / agent B alters factor / agent A status

$\mathrm{A}>\mathrm{B}$

Factors / agents A and B simultaneously alter each other

$\mathrm{A}<\mathrm{B}$

Factors / agents A and B are or become (temporarily) disconnected

$\mathrm{A}<>\mathrm{B}$

A X B

Table 3. Factors / agents primary and secondary interactions within design process.

\begin{tabular}{|c|c|c|}
\hline Complexity criteria & Primary interactions & Secondary interactions \\
\hline \multirow[t]{3}{*}{ Connectivity } & $\mathrm{A} \leftrightarrow \mathrm{B}$ & $\mathrm{A}>\mathrm{B}$ \\
\hline & $\mathrm{A} \rightarrow \mathrm{B}$ & $\mathrm{A}<\mathrm{B}$ \\
\hline & $\mathrm{A} \leftarrow \mathrm{B}$ & \\
\hline \multirow[t]{2}{*}{ Autonomy } & $A \bigcirc B$ & $\mathrm{~A} \propto \mathrm{B}$ \\
\hline & A X B & $\mathrm{A}<>\mathrm{B}$ \\
\hline \multirow[t]{3}{*}{ Emergence } & $A \bigcirc B$ & $\mathrm{~A}<>\mathrm{B}$ \\
\hline & $\mathrm{A} \approx \mathrm{B}$ & \\
\hline & $\mathrm{A} \propto \mathrm{B}$ & \\
\hline \multirow[t]{3}{*}{ Non-equilibrium } & $\mathrm{A} \approx \mathrm{B}$ & $\mathrm{A}>\mathrm{B}$ \\
\hline & $\mathrm{A} \propto \mathrm{B}$ & $\mathrm{A}<\mathrm{B}$ \\
\hline & & $\mathrm{A} X \mathrm{~B}$ \\
\hline \multirow[t]{4}{*}{ Nonlinearity } & $\mathrm{A} \approx \mathrm{B}$ & $\mathrm{A}<>\mathrm{B}$ \\
\hline & $\mathrm{A}>\mathrm{B}$ & \\
\hline & $\mathrm{A}<\mathrm{B}$ & \\
\hline & A X B & \\
\hline \multirow[t]{7}{*}{ Self-organization } & $\mathrm{A} \leftrightarrow \mathrm{B}$ & $\mathrm{A} \bigcirc \mathrm{B}$ \\
\hline & $\mathrm{A} \rightarrow \mathrm{B}$ & $\mathrm{A} \approx \mathrm{B}$ \\
\hline & $\mathrm{A} \leftarrow \mathrm{B}$ & $\mathrm{A} \infty \mathrm{B}$ \\
\hline & $\mathrm{A}>\mathrm{B}$ & \\
\hline & $\mathrm{A}<\mathrm{B}$ & \\
\hline & $\mathrm{A}<>\mathrm{B}$ & \\
\hline & $\mathrm{A} X \mathrm{~B}$ & \\
\hline \multirow[t]{5}{*}{ Co-evolution } & $\mathrm{A} \approx \mathrm{B}$ & $\mathrm{A} \leftrightarrow \mathrm{B}$ \\
\hline & $\mathrm{A}>\mathrm{B}$ & $\mathrm{A} \rightarrow \mathrm{B}$ \\
\hline & $\mathrm{A}<\mathrm{B}$ & $\mathrm{A} \leftarrow \mathrm{B}$ \\
\hline & $\mathrm{A}<>\mathrm{B}$ & \\
\hline & A X B & \\
\hline
\end{tabular}


Another example of complexity management was the establishment of program of new OOK. On the one hand it required expert driven approach and expert knowledge to propose and to formulate the program. On the other hand it could not be acquired without the participation of current staff of the cultural center, and what's more without acknowledging the needs of amateur bands contributing to the cultural output of the community, having aspirations of being able to permanently use the final OOK architectural complex. Vox populi was also necessary to be included, mainly for knowledge generation and socio-political reasons - to enable extension to financial support for this development [23]. This pointed out towards participatory design elements, and ultimately strongly influenced the decision on splitting the task on four different stages - A, B, C and D (Figs. 1 \& 2). This contribution was validated

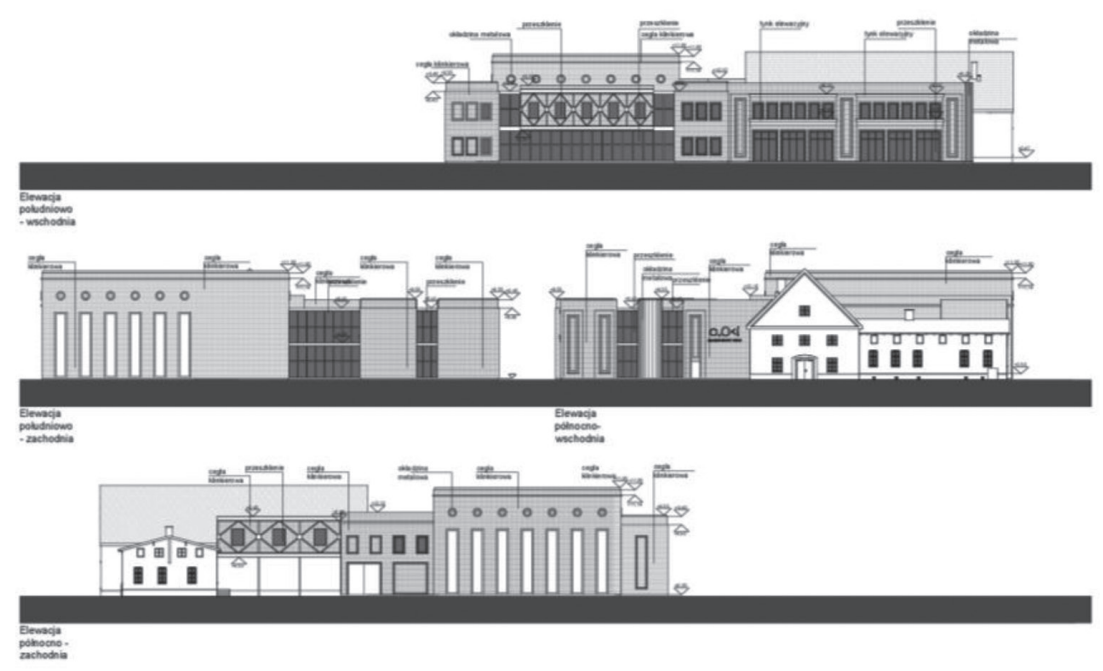

Figure 1: Stage A of the OOK project - facades.

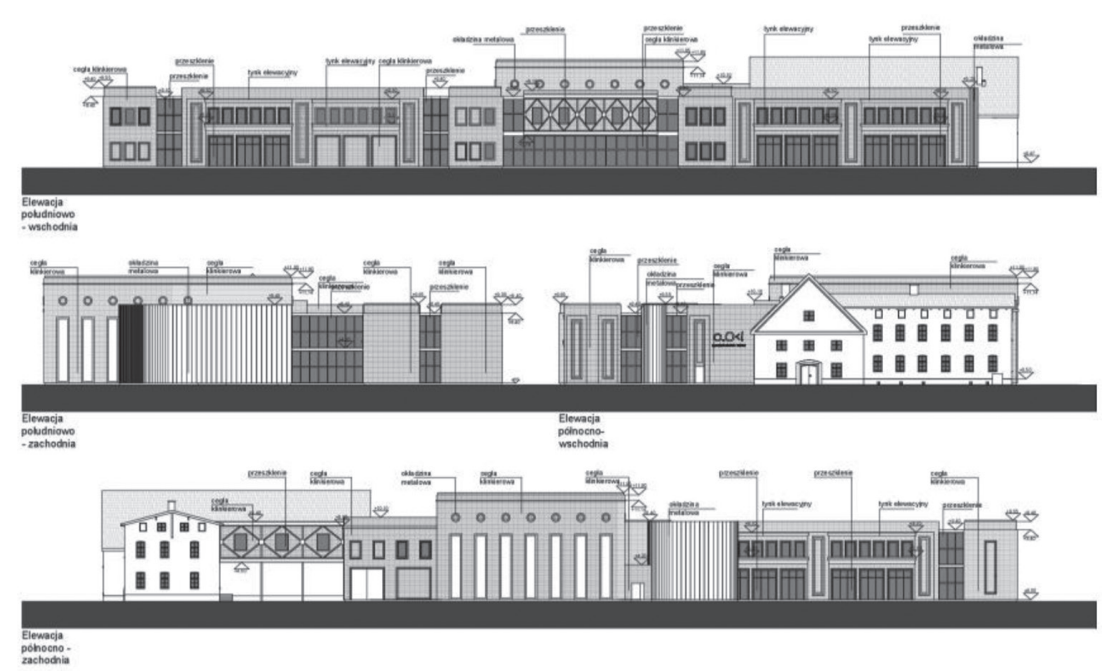

Figure 2: Stage $\mathrm{A}+\mathrm{B}+\mathrm{C}+\mathrm{D}$ of the OOK project - facades. 
by over 600 respondents, voting for both conceptual solutions and programmatic solutions, and independent elaboration - report - has been produced as a result [24].

The project has been conducted while performing fragmentary participation procedures which lasted for over one year, almost as long as the design itself $[25,26]$. It is hardly possible to include community in all key decisions, and hard to organize smooth coordination, therefore design of the center had to be processed and changes induced by potential participatory or external influential factors taken into account during the advancement of defining the architectural shape of new OOK. According to the administration of the cultural center (currently operating) the temporary importance chart for programmatic contents presented itself as (in order of importance): multifunctional auditorium to host multiple artistic events and accommodate artistic activity of multiple bands performing in Oborniki, multifunctional hall, and service areas for performers. Architects' own recognition of needs of community and local bands, but the results of the report exposed the necessity to adjust the programming of the center with the inclusion of a cinema, which in turn, due to some related feasibility analysis launched in relevance, forced the adaptation of multifunctional auditorium to adopt the possibility to be temporary converted into cinema as well [27]. One specialized cinema and two auditoriums with projection rooms added and appropriate equipment granted (Fig. 3).

The project was performed with 6 preliminary organization and architectural concepts, proposing diverse typologies for new OOK (cultural center). Two parallel, evolved concepts were used as potential vessels for spatial and visual identity (with attributed names of Quartz and Showroom, with the latter adopted for final elaboration [Fig. 4]). Even final concept, selected with participation of local authorities and wide group of inhabitants of Oborniki administrative area, was several times altered due to various factors - economic, related to limitation in budget of the development, programmatic, due to will to maintain the overall spatial disposition, or formal derived from cultural code recognized by local community and available in some places of Oborniki as part of its architectural heritage - and OOK as associated volume.

Table 4 exposes selected elements of complexity management within the design process. These are fragmentary and their description due to attributes of complexity cannot be fully explained verbally while not only this implies design process structure vast and

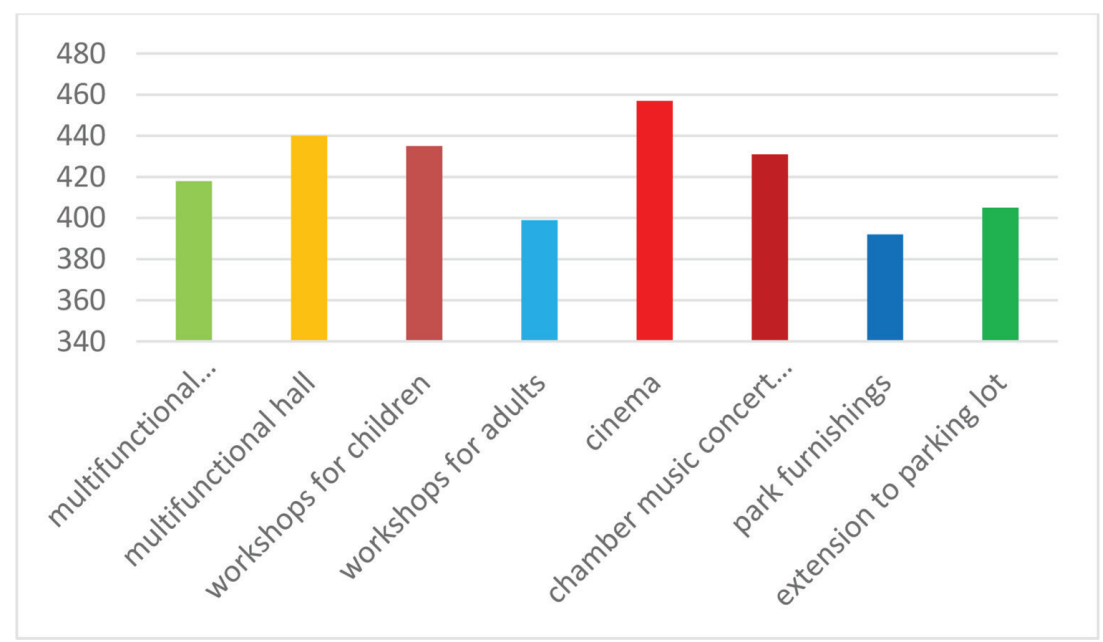

Figure 3: Results of community members' voting for programmatic bias (first 8 positions). 
Table 4. Examples of complexity application in OOK project.

Complexity criteria Architectural design process (examples)

Connectivity Intradisciplinary and interdisciplinary networking roof and gallery definition affecting installation design (HVAC and lighting) and vice versa, energy balance affecting roof structure, form, and skylights distribution technical section is designed in anticipation of future stages to be performed separately, which includes e.g. installation transfers

Autonomy

Emergence

Non-equilibrium

Nonlinearity

Self-organization

Co-evolution
Ability to accommodate exclusive specialized cinema hall was designed as separate, autonomous section of cultural center, with distinct material selection, to maintain future possibility to include or exclude cinema after it was ruled out that stage $\mathrm{D}$ will be joint with stage A recording room section retain autonomy throughout the entire process

Inclusion (responsive) mechanisms inclusion of summer stage design (required) the project initiates social interest, reaction, and expectations, feeding the process 'recycling of material' thread (interior identity anchor)

Permanent fluctuation (flexible structure) permanent multiple factors management through the course of design

Open architecture of the process programmatic adjustments (impact of participatory design content) organization of development stage implementations ( 1 stage to 3 stage to 4 stages ultimately)

Permanent reconfiguration (flexible structure) multiple re-orientation of design course shifts in temporary established hierarchies splitting design process into stages and parallel elaboration of selected elements (e.g. changes of setting of particular contents of the center, obscured facades design)

Permanent evolution of contents of the process (flexible structure) responsive modules within the process anticipation of technologies to be replaced in future programming the process of wearing of architectural substance (use cycles)

multidirectional network, but constant flux of its components. Some connections between factors disappear, others emerge.

Complexity is merged with Meta-Design methodology, which has been frequently applied since 2007, its formulation, analysis, and primary implementations performed in several public sector and private sector commissions. Meta-Design (M-D) connects well with complexity theoretical assumptions. First of all M-D acknowledges and accommodates fundamental shifts in design criteria in its 'meta' project timeline [28]. It includes the idea redefinition option, it retains factors like idea, program, and even the theme (topics) as open ones. It encourages simultaneous autonomization and increased connectivity between contents of the process. While this paper is not intended to describe M-D, its reference serves here the purpose of proving successful implementation of complexity principles in already established and successful design methodology. 


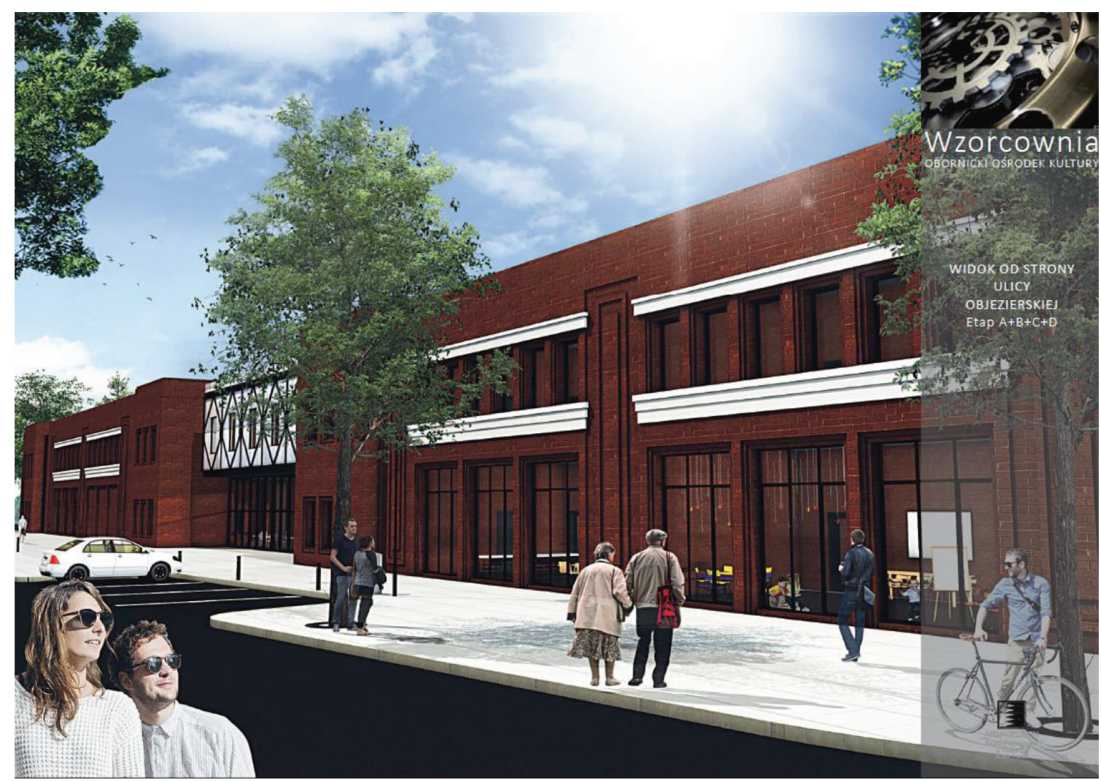

Figure 4: Superficial form of OOK project upon completion of current stage (overall design for 4 stages).

\section{CONCLUSION}

Based on current implementations it is impossible to understand how far complex system may become the main framework of architectural design process, but there is no doubt that the system may and should be embedded into the process to reflect the complexity of the real which is to be depicted in the architectural works. The limits on complex system application is mostly related to human related factors, those same factors that dictate the response of the methodological framework of design process so well facilitated by the complex system elements. This topic has been discussed by Alexander himself [29] advocating for presence of subjective, worldview oriented and inherent bias, which in the theory of science is proven to be inextricable and unavoidable. The observation exposes specific architectural character of project which is rooted in axiology, and connected to human evolution integrated into the project principles. As Alexander puts it in a straightforward manner - generative / evolving architecture is always about living structures, which can be understood as living spaces transformed by people, and is always saturated with ethical (or moral) content [30].

Whether limitations of the system can be overcome remains to be seen, but definitely complexity proves its applicability and relevance in architectural implementations, and responds to what Halina Dunin-Woyseth and Fredrik Nilsson [31] describe as new focus of contemporary progressive practices which is the reflection of social complexity in modern architecture performed in multifaceted urban environments, resulting in going beyond what was traditionally claimed to be architecture. But this innovation still is sinful, still lingers in formal superficial layers of architectural information, so aptly named by Mehaffy and Salingaros architectural myopia. As they elaborately conclude in their considerations, we all:

(...) must reform the architecture (...-...) without further delay, and place a new emphasis on design that is evidence-based, that pays attention to postoccupancy evaluations, and that, in short, values the outcome for human beings and takes their needs seriously. [32] 
and this is the area that application of complexity, at least in design processes already performed by research team, may excel at.

\section{REFERENCES}

[1] Buckminster Fuller, R., Inventory of world resources. human trends and needs. Southern Illinois University, Carbondale, 1963.

[2] Bürdek, B.E., Design-Theorie. Methodische und systematische Verfahren im Industrial Design, Ulm, 1971.

[3] Asimov, M., Introduction to design, Prentice Hall, Englewood Cliffs, 1962.

[4] Krick, E.V., An introduction to engineering and engineering design. John Wiley and Sons, New York, 1969.

[5] Zeisel, J., Inquiry by design. W. W. Norton \& Company, New York, 2006. See 27-29. (First edition was published in 1981).

[6] Alexander, C., New concepts in complexity theory arising from studies in architecture: an overview of the four books of the nature of order with emphasis on the scientific problems which are raised. Katarxis, 3, p. 24, 2003, available at: www.katarxis3.com/. (accessed 10 March 2017).

[7] Shoshkes, E., The design process. case studies in project development. Whitney Library of Design, New York, 1989.

[8] Farrelly, L., The fundamentals of architecture. AVA Publishing, Lausanne, p. 160, 2007.

[9] Rowe, P.G., Design thinking. The MIT Press, Cambridge, 1995.

[10] Handler, A.B., Systems approach to architecture. American Elsevier Publishing Company, New York, 1970.

[11] Lang, J., Creating architectural theory: the role of the behavioral sciences in environmental design. Van Nostrand Reinhold Co., New York, 1987.

[12] Picon, A., Continuity, complexity and emergence: what is real for digital designers? Perspecta, 42, pp. 147-157, 2010.

[13] Ibid.: pp. 156-157.

[14] Op. cit., Alexander, 2003: 9.

[15] Mehaffy, M. \& Salingaros, N. A., Architectural myopia: designing for industry, not people. On the Commons, pp. 10, 5 and 9.

[16] Rzevski, G. \& Skobelev, P., Managing complexity, WIT Press, Southampton, 2014.

[17] Upitis, R., School architecture and complexity. Complicity: An International Journal of Complexity and Education, 1(1), pp. 19-38, 2004.

[18] Bektaş, E., Knowledge sharing strategies for large complex building projects, architecture and the built environment (No. 04). Delft University of Technology, Delft, The Netherlands. See 139-140, 147-150.

[19] Op. cit., Rzevski and Skobelev, pp. 30-31, 2014.

[20] Barelkowski, R., The laboratory of theory-practice induction meta-circle. On approaches to architectural design process. Proceedings from International Conference Impact by designing, Sint Lucas School of Design, Brussels, 2017, April 6th-7th.

[21] Cf. Op. cit., Mehaffy and Salingaros, p. 9, 2011.

[22] Escobar, A., Notes on the ontology of design. University of North Carolina, Chapel Hill, 2012. See 41-43.

[23] Anderson, N., Public interest design: expanding architecture and design through process and impact. In J. Cohen-Cruz (ed.), Hybrid, evolving, and integrative career paths, Vol. 2, Issue 2, A Journal of Imagining America, pp. 26, 2014. See 12. 
[24] Barelkowski, R., Barelkowska, K., Chlasta, L., Rosiak, L. \& Wardeski, L., Opinia lokalnej spolecznosci na temat stanu infrastruktury kulturalnej na terenie Gminy Oborniki $i$ priorytetowych potrzeb $w$ zakresie jej uzupełnienia. Raport dot. analizy wynikow (Report on results of the research) 2, September 2016, Armageddon Biuro Projektowe, Poznan Oborniki, September 2016. See 7.

[25] Barelkowski, R., Barelkowska, K., Chlasta, L., Rosiak, L. \& Wardeski, L., Opinia lokalnej spolecznosci na temat stanu infrastruktury kulturalnej na terenie Gminy Oborniki $i$ priorytetowych potrzeb $w$ zakresie jej uzupełnienia. Raport dot. analizy wynikow (Report on results of the research), Armageddon Biuro Projektowe, Poznan - Oborniki,.

[26] Op. cit., Barelkowski et al., 2016.

[27] Feasibility exposed that it is financially unreasonable to have one small cinema. Therefore hybrid multiplex with maximum of 3 potential cinema auditoriums has been considered.

[28] Barelkowski, R., Meta-design versus self-contained design. In A. Dutoit, J. Odgers, A. Sharr (eds.), Quality, Welsh School of Architecture in Cardiff, Cardiff, pp. 23, 2007.

[29] Op. cit., Alexander, p. 13, 2003.

[30] Ibid.: 16.

[31] Dunin-Woyseth, H. \& Nilsson, F., Design education, practice, and research: on building a field of inquiry. Studies in Material Thinking: Re/materialising Design Education Futures, 11, pp. 3-17, 2014. See 8.

[32] Op. cit., Mehaffy and Salingaros, 2011: 9. From the second brackets word "school" was removed, while author believes the idea was to spread this kind of approach to currently operating professional practices, too. 